\title{
INGINKAH ANDA MEMPUNYAI BANYAK PASIEN ?
}

\author{
Endang Sariningsih
}

\author{
Private Practitioner
}

\section{Keywords : \\ In regard to the above considerations, You will get lots of patients.}

\begin{abstract}
In this global era the quality of dental service in Indonesia has become increasingly competitive, which can be reflected in the increasing number of traditional dental service, private dental practice, public health service, 24 hour health clinic, dental clinic, specialist dental clinic and dental spa. Dentists need to consider an appropriate service method and to determine the patient's specific target so that they could become a loyal customer. The first important consideration in order to satisfy customer a dentist has to be updated with the latest dentistry development, dental equipment and material, so that he is able to apply the latest dental techniques with sophisticated equipment and materials. The second point is the dental service quality, the dentist meticulousness and carefulness to execute every case. The third point is the best dental service of the dentist and his team, hospitality, punctuality, strategic practice location and interior practice hygiene. The last important point is to determine the patient's specific target market based on dentist's competitive skill and local people characteristic.
\end{abstract}

\section{Pendahuluan}

Dalam menjalankan tugas profesinya, dokter gigi saat ini dan dimasa mendatang dihadapkan pada situasi yang sangat kompetitif. Semakin banyak ragam pelayanan kesehatan gigi menyebabkan semakin berkurang jumlah pasien yang datang ke suatu tempat praktek dokter gigi. Masalah tersebut harus menjadi tantangan bagi seorang dokter gigi untuk mencari peluang untuk mendapatkan pasien sehingga jumlah pasien yang datang ketempat praktek tidak berkurang, dan bahkan bertambah. Dalam makalah ini akan dibahas kiat atau cara dokter gigi agar memperoleh banyak pasien.

\section{Strategi untuk memperoleh kunjungan pasien \\ Untuk memajukan prakteknya seorang dokter gigi harus mempunyai rencana.. Lakukan}


setiap rencana tersebut secermat dan sesempurna mungkin ${ }^{2}$, kemudian pikirkan strateginya. Strategi untuk memperoleh kunjungan pasien adalah sebagai berikut :

a. Berorientasi pada apa yang dikehendaki dan dicari oleh masyarakat/pasien.

Masyarakat / pasien biasanya mengharapkan dokter gigi yang dapat memberikan pelayanan yang efektif dan efisien. Efektif artinya bermutu; efisien artinya dengan biaya wajar ${ }^{9}$. Selain itu dokter gigi juga perlu mengenal tingkat ekonomi pasar yang dituju, segmen kelas konsumen yang akan menjadi target pelanggannya.

b. Berorientasi pada kepuasan pasar.

Ada 2 tujuan pokok, seorang pasien berobat ke dokter gigi yang dipilihnya.

Tujuan pertama adalah untuk mendapatkan diagnosis yang tepat dan mendapatkan perawatan secara kompeten dan wajar.

Tujuan kedua adalah dokter gigi mampu menghilangkan rasa cemas dan takut yang menyertai keadaan sakit tersebut. Jadi, dalam praktek dokter gigi, kepuasan ditentukan oleh pada kemampuan menghilangkan rasa cemas dan takut, kemampuan medis teknis serta kepribadian dokter gigi ${ }^{9}$.

c. Profesionalisme

Dokter gigi seharusnya berpraktek secara benar, artinya dapat dipertanggung jawabkan secara ilmiah, sesuai dengan tingkat kemajuan IPTEK mutakhir dan metode-metode yang telah teruji 9 Dokter gigi sebaiknya senantiasa mengemb angkan diri sesuai dengan kemajuan ilmu pengetahuan dan teknologi secara tepat guna melalui penambahan ilmu. Penguasaan bahasa Inggris sangat penting agar bisa membaca literatur dalam bahasa Inggris, juga bila ada pasien orang asing ${ }^{8}$.

Dokter gigi beserta semua anggota tim, harus berkomitmen secara menyeluruh pada mutu. Semua pekerja harus belajar untuk melakukan pemeriksaan mutu ${ }^{7}$.

d. Service (pelayanan)

Pelayanan harus memuaskan dan memenuhi keinginan serta kebutuhan pasien.
Cara dokter gigi beserta timnya melayani pelanggan, sangat berpengaruh terhadap kunjungan pelanggan. Layanan yang berbeda dengan tempat pelayanan yang lain, akan langsung diingat oleh pelanggan ${ }^{2}$.

Kenyamanan, keramahan, keakraban, waktu menunggu yang tidak lama, merupakan kunci keberhasilan pelayanan ${ }^{6}$.

e. Menciptakan identitas dan citra tempat praktek.

Identitas tempat praktek berorientasi pada kekhususan yang ditampilkan, sedangkan citra tempat praktek adalah ciri-ciri yang melekat pada alam perasaan pasien yang datang ${ }^{3}$.

f. Melengkapi ijin-ijin dan peraturan yang diperlukan.

Ijin dan peraturan tempat praktek meliputi Surat Ijin Praktek (SIP) dan Nomor Pokok Wajib Pajak (NPWP) ${ }^{3}$.

\section{Kiat mendapatkan kunjungan pasien yang banyak}

Setiap dokter gigi pasti menginginkan agar tempat prakteknya banyak dikunjungi pasien.

Kiat agar keinginan tersebut tercapai adalah sebagai berikut :

a. Merencanakan seluruh kebutuhan untuk praktek.

b. Merencanakan segmen kelas konsumen mana yang akan menjadi target pelanggan, mengingat lokasi dan lingkungan tempat praktek, karakteristik masyarakat setempat, keahlian dokter gigi, penataan interior ruang tunggu dan ruang praktek.

c. Melengkapi ijin-ijin dan peraturan yang diperlukan misalnya: SIP (Surat Ijin Praktek), NPWP dan STR (Surat Tanda Registrasi) sesuai dengan Undang-Undang Praktek Kedokteran tahun 2004. Kelengkapan ijin-ijin dapat membawa kepercayaan dan ketenangan bagi pasien ${ }^{3}$.

d. Meningkatkan keterampilan dan pengetahuan kedokteran gigi dengan cara mengikuti seminar dan kursus-kursus keterampilan serta menjadi spesialis.

Meningkatkan frekuensi keikut sertaan dalam pertemuan ilmiah baik nasional maupun internasional serta mengikuti 
perkembangan teknologi baru, juga merupakan cara seorang dokter gigi dapat meningkatkan kemampuannya ${ }^{8}$.

e. Menciptakan identitas dan citra ditempat praktek.

Identitas ditempat praktek meliputi banyak aspek yang ditampilkan secara khusus.

- Gedung/tempat praktek dengan desain interior yang bagus.

- Suasana ruang tunggu, ruang praktek yang nyaman.

- Sarana peralatan yang lengkap.

- Keahlian/spesialisasi.

Citra ditempat praktek meliputi banyak aspek :

- Mutu/kualitas pelayanan yang baik.

- Keramah tamahan dokter gigi beserta timnya.

- Disiplin waktu buka dan tutup, sesuai yang tertera dipapan nama.

- Waktu menunggu yang tidak lama.

- Kebersihan gedung dan tempat praktek yang higienis, sterilitas peralatan kedokteran gigi.

- Ketelitian dan kejelian dalam menangani suatu kasus.

f. Memberikan layanan (dokter gigi beserta timnya) kepada pasien dengan sebaikbaiknya, sesuai kebutuhan pasien.

g. Memberikan konsultasi kepada pasien, jasa apa saja yang bisa diberikan kepada mereka, sesuai kebutuhannya.

h. Menetapkan biaya pelayanan yang pantas, memberi informasi tentang biaya perawatan giginya secara terperinci, sebelum seorang dokter gigi melakukan perawatan. Hal ini perlu untuk menghindari keluhan pelanggan tentang biaya perawatan yang harus dikeluarkannya.

i. Pasien diberi pilihan/alternatif perawatan beserta besarnya biaya perawatan.

j. Metode pelayanan praktek diubah dari kuratif ke preventif, promotif serta rehabilitatif, sehingga cakupan pelayanan dokter gigi menjadi lebih luas karena pelanggan yang sehat lebih banyak daripada yang sakit ${ }^{8,9}$.

k. Anggota tim/staf dokter gigi diberi insentif tiap minggu/bulan sesuai pendapatan yang diperoleh dokter gigi yang berpraktek, sehingga mereka dapat merasakan imbalan yang lebih, bila jumlah pasien meningkat. Anggota tim ini bisa membantu dalam memberikan infor masi/keterangan tentang hal-hal yang diperlukan pelanggan, dimana kadangkadang pelanggan menanyakan kepada anggota tim, sebelum bertemu dengan dokter giginya.

l. Mengumpulkan bahan-bahan yang diperlukan untuk pertemuan dan peningkatan sumber daya manusia serta mengadakan pertemuan/diskusi secara berkala, sesuai kebutuhan.

m. Dokter gigi bisa bekerja sama dengan anggota tim sehingga tujuan pelayanan tercapai, yaitu demi kesembuhan dan kepuasan pa sien/pelanggan.

Dokter gigi bisa bekerjasama dengan dokter umum mendirikan klinik bersama untuk meningkatkan mutu pelayanan.

n. Dokter gigi bekerja dengan hati nurani, selalu melaksanakan pelayanan kepada pasien sesuai kompetensi dan kemampuan ${ }^{5}$. Dengan memperhatikan faktor-faktor diatas, pelanggan akan berpaling kepada anda.

\section{Kesimpulan}

Dokter gigi dapat meningkatkan kunjungan pasien ditempat praktek dengan mengubah metode pelayanan praktek dari kuratif ke preventif, promotif dan rehabilitatif.

Selain itu perlu diusahakan peningkatan mutu pelayanan, bekerja secara profesional, bekerja sama dengan anggota tim dan melayani dengan hati nurani.

\section{Daftar Pustaka}

1. Adiningrum Wiradidjaya Adiwoso DDS. Quality of Dental Care. Makalah Seminar PDGI Jakarta. 15 April 2000.

2. Ariyadi Abimanyu, Buku Pelajaran Marketing. Ed.1. Gunung Agung 2003: 57-131. 
3. Bulan Rahmadi, Upaya Memperoleh Kunjungan Pasien di Tempat Praktek. Jurnal Kedokteran Gigi Indonesia Ed. 3; Desember 2001: 11-16.

4. Fandi Tjiptono, Strategi Bisnis. Ed. II. Andi Jogyakarta 2002: hal 37.

5. Haryanto A.G, Etika Sebagai Bagian Sikap Pelayanan serta Sikap Hidup Seorang Dokter Gigi. Dentist: 2006

6. Mardiati Najib, Pemasaran Produk Pelayanan Kesehatan Gigi. Makalah Seminar PDGI. Jakarta: 2000.
7. Olga L Crocker, Gugus Kendali Mutu. Ed. IV, PT. Bumi Aksara, 2004: 26.

8. S.W. Prayitno, Persiapan Dokter Gigi dalam Menghadapi Peluang dan Ancaman Sistem Pasar Bebas. Diskusi Panel : Profil Dokter Gigi dalam Era Globalisasi, Foril V 1996 FKG Usakti, Jakarta 7-10 Oktober 1996 ; Hal 10-15

9. Zaura Matram, Ketangguhan Dokter Gigi di Era Kompetisi. Jurnal Kedokteran Gigi Indonesia. Ed. 3; Desember 2001: 5-10. 